\title{
Stage IV Vulvar Cancer AJCC v7
}

National Cancer Institute

\section{Source}

National Cancer Institute. Stage IV Vulvar Cancer A/CC V7. NCI Thesaurus. Code C89453.

Stage IV includes: IVA: (T1/T2, N3, M0); (T3, Any N, M0); IVB: (Any T, Any N, M1). T1:

Invasive vulvar cancer confined to the vulva or perineum. T2: Vulvar cancer with tumor of any size with extension to adjacent perineal structures (lower/distal 1/3 urethra, lower/distal 1/3 vagina, anal involvement). T3: Vulvar cancer with tumor of any size with extension to any of the following: upper/proximal 2/3 urethra, upper/proximal 2/3 vagina, bladder mucosa, rectal mucosa, or fixed to pelvic bone. N3: Vulvar cancer with fixed or ulcerated regional lymph node metastasis. M1: distant metastasis (including pelvic lymph node metastasis). (AJCC 7th ed.) 